\title{
A biblioteca pública e os domínios da memória, da mediação e da identidade social
}

\author{
Henriette Ferreira Gomes
}

\begin{abstract}
Professora Titular do Instituto de Ciência da Informação (ICI) da Universidade Federal da Bahia (UFBA). Chefe do Departamento de Documentação e Informação do ICI/UFBA e docente do corpo permanente do Programa de Pós-Graduação em Ciência da Informação (PPGCI) da UFBA.
\end{abstract}

http://dx.doi.org/10.1590/1981-5344/2264

Como resultado de pesquisa bibliográfica o texto aborda brevemente o percurso histórico da biblioteca enquanto espaço social de cultura, buscando evidenciar os contextos que fizeram emergir três paradigmas que nortearam o trabalho da biblioteca: da conservação, difusão e apropriação cultural. Tais paradigmas definiram as funções da biblioteca pública. Entretanto, o paradigma da apropriação cultural foi promotor de uma consciência mais clara quanto ao lugar relevante da mediação da informação. Ao posicionar a apropriação cultural na centralidade da missão desse ambiente social, os comportamentos e necessidades dos seus usuários conquistaram o status de objeto de atenção para o desenvolvimento do trabalho com a informação, tornando mais evidente a condição da biblioteca enquanto espaço de mediação cultural. Esse debate aponta a urgência de ressignificação das atividades e práticas culturais desenvolvidas pela biblioteca, como também de suas práticas gestoras, de modo a assegurar uma perspectiva dialógica do seu trabalho, necessária ao processo de mediação e apropriação da informação. Conclui-se que a constituição e preservação da memória foram elementos determinantes do aparecimento da biblioteca, enquanto o "olhar" para os comportamentos e necessidades dos usuários foi determinante dos debates acerca da mediação e apropriação da informação. Na atualidade a biblioteca pública é convocada a atuar tanto no domínio da memória, quanto da mediação e da identidade social, desenvolvendo ações orientadas por esses três paradigmas que circunscreveram sua própria existência. Transitar pelos paradigmas da conservação, da difusão e 
da apropriação cultural é o desafio a ser enfrentado pela biblioteca pública no cumprimento de sua missão social.

Palavras-chave: Biblioteca pública. Mediação da informação. Memória. Identidade social. Apropriação cultural.

\section{The public library and the domains of memory, mediation and social identity}

As a result of literature search, the present work briefly discusses the historical background of the library as a cultural space, evidencing the contexts that did emerge three paradigms, guides of library's work: the preservation, dissemination and cultural appropriation. Such paradigms defined the functions of the public library. However, the paradigm of cultural appropriation was promoter of the clearer awareness about the relevant place of the mediation of information. By positioning the centrality of cultural appropriation in the mission of this social environment, behaviors and needs of its users acquired an attention status for the development of working with the information, making it clear the condition of the library as a space of cultural mediation. This debate highlights the urgency in reframing cultural practices and activities developed by the library, and also their management practices, to ensure a dialogical perspective of its work, requirement for mediation and appropriation of the information. In conclusion, the formation and preservation of memories were crucial elements to cause library's appearance, whereas the "look" for behaviors and needs of its users was crucial for debates about mediation and appropriation of the information. At present, the public library is called to act in the domains of memory, mediation and social identity, developing actions guided by these three paradigms that circumscribed their own existence. Go through the paradigms of conservation, dissemination and cultural appropriation is the challenge to be faced by the public library.

Keywords: Public library. Mediation of information. Memory. Social identity. Cultural appropriation

Recebido em 11.11.2014 Aceito em 13.11.2014 


\section{Introdução}

Abordar a biblioteca pública considerando os domínios da memória, da mediação e da identidade social obriga, ainda que de modo ligeiro e abreviado, que se rememore a própria trajetória histórica desse ambiente de informação, perseguindo os pontos sinalizadores da sua ligação com os mesmos.

Ao se revisitar tal percurso constitutivo do ambiente biblioteca enquanto espaço social de cultura torna-se evidente os três paradigmas norteadores da sua existência, o paradigma da conservação cultural, da difusão cultural e da apropriação cultural. Sob esses três paradigmas a biblioteca foi sendo tecida como um ambiente informacional, responsável socialmente não apenas pela preservação do patrimônio cultural da humanidade, mas também como um espaço agenciador da disseminação da diversidade e expressão cultural, e dos processos de apropriação da informação, geradores da criatividade, da inovação e da geração de sentidos.

As mudanças históricas que moveram o nascimento desses paradigmas introduziram em suas gêneses funções sociais à biblioteca pública que não se anulam, não são excludentes, mas sim inclusivas. Por outro lado, a consciência mais clara de que a apropriação cultural encontra-se na centralidade da missão desse ambiente social colocou o usuário e suas necessidades em lugar de relevo no trabalho com a informação, trazendo à tona a importância do papel mediador da biblioteca e dos profissionais que nela atuam.

Para abordar tais questões, este trabalho resulta de uma pesquisa de caráter bibliográfico, a partir da qual se tornou possível refletir acerca das contribuições de autores da própria Ciência da Informação, como também dos campos da Filosofia, História, Educação e Psicologia na análise da biblioteca pública sob a perspectiva dos domínios da memória, da mediação e da identidade social.

Como resultado o texto apresenta considerações acerca da constituição de memórias e da preservação delas como elementos que determinaram o aparecimento social da biblioteca; o contexto mobilizador de um "olhar" mais atento para os comportamentos e necessidades dos usuários e a influência desse movimento na instauração dos debates acerca da mediação da informação, voltada à sua apropriação.

\section{A constituição e a preservação da memória: fatores determinantes do nascimento da biblioteca}

Desde a "infância" da humanidade os homens perceberam a necessidade da constituição de memórias. Com esse objetivo se desenvolveram as narrativas, os desenhos, pinturas e gravuras e, como expansão desse processo, 0 aprimoramento das linguagens e a sua representação escrita, possibilitando, com isso, o desenvolvimento dos manuscritos. 
Esse processo representou e permitiu que mitos, crenças, valores morais, percepções de mundo, os conhecimentos e a cultura pudessem ser registrados, colecionados e preservados. Enfim, permitiu que o saber acumulado a partir da vida e da observação dos fenômenos pudesse ser compartilhado, expandindo o espaço da intersubjetivadade. Com o tempo os grupos sociais agregaram a essa experiência a necessidade de organizar a informação registrada, constituindo meios mais eficazes para se ter acesso aos conteúdos informacionais em qualquer tempo. Esse desdobramento decorreu de dois tipos de comportamento humano: 0 comportamento comunicacional e o comportamento preservacionista, cuja gênese advém da busca da estabilidade social e cultural, significando o principal substrato do domínio da formação de memórias. Assim, pode-se inferir que tais comportamentos sustentaram as ações que deram início à formação das primeiras bibliotecas e, consequentemente, das primeiras práticas biblioteconômicas.

Por séculos as práticas biblioteconômicas foram desenvolvidas à luz de um conhecimento empírico, que deram sustentação à formação de vários acervos ao longo da história. Na Antiguidade e na Idade Média os acervos foram formados pela nobreza e pelo clero, com o objetivo de se desenvolver e consolidar a erudição dessas categorias sociais, mas com o foco central da formação cultural das lideranças políticas e religiosas. Esse contexto colocou a biblioteca como lócus do fazer informacional sob o domínio da formação e conservação da memória, concentrando sua atuação nos processos de mediação indireta que, à luz do conceito de mediação da informação de Almeida Júnior (2008), vincula-se às atividades de organização e representação da informação.

Mas, em fins do Século XIII e início do Século XVII, o mundo viveu a efervescência do Renascimento, período histórico marcado por transformações em muitos setores da vida em sociedade, que assinalaram o final da Idade Média e o início da Idade Moderna.

A ocorrência da Revolução Francesa demarcou a forte influência do Iluminismo e o aparecimento do Estado de direito, resultantes e ao mesmo tempo inspiradores e impulsionadores de várias lutas, incluindo-se com muita ênfase os direitos de acesso ao conhecimento e de socialização dos saberes. No entanto, uma barreira importante para a viabilização desses direitos consistia na existência de grandes massas de analfabetos, uma parcela muito reduzida da população poderia ser considerada letrada, parcela esta concentrada entre os membros da nobreza e do clero. Essa realidade, no contra ponto aos ideais iluministas e aos direitos de acesso aos saberes e a cultura, fez surgir a figura dos mediadores de leitura (MANGUEL, 1997, p. 130), como ilustra da figura de Marillier em representação de uma cena de leitura pública, realizada na França do Século XVIII.

Figura 1 - Cena de leitura pública 


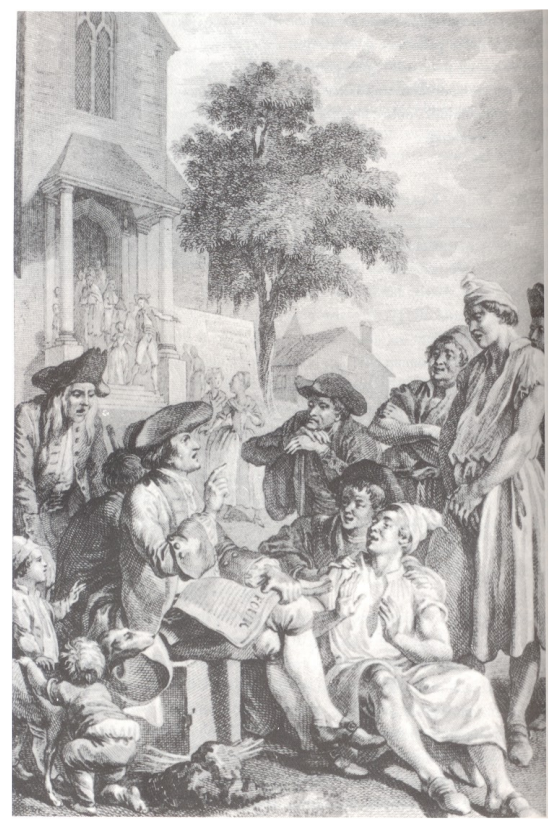

Fonte: Manguel, 1997, p. 130.

Com o Renascimento ocorreu a institucionalização e a expansão das escolas e das bibliotecas, como espaços sociais de aprendizagem, formação e constituição cultural. Nesse diapasão o objeto informação começou a trilhar o caminho da conquista de um novo status que superava sua característica primeira de conhecimento registrado para a preservação, fazendo com que a biblioteca, na condição de ambiente informacional, alcançasse os primeiros contornos de atuação para além do domínio da memória.

Esse período histórico pode ser considerado como "ponto de largada" da construção de uma compreensão da informação enquanto objeto de grande valor para o desenvolvimento social e para a renovação das idéias. Assim, as bibliotecas começaram a ser entendidas como um ambiente relevante para a socialização dos saberes.

No entanto, foi a partir dos adventos da Revolução Industrial e das duas Grandes Guerras Mundiais que se tornou mais evidente a necessidade de informação para o desenvolvimento científico, tecnológico, econômico e social. A ascensão da informação a um objeto de relevante valor social motivou todos os empreendimentos de pesquisa no campo biblioteconômico, com ênfase na organização, representação, disseminação e recuperação da informação, na busca da facilitação dos processos de acesso e uso. Esse foi o contexto do nascimento da Biblioteconomia Especializada, como também 0 terreno sob 0 qual emergiu o campo da Ciência da Informação.

A expansão das atividades científicas, o acelerado desenvolvimento tecnológico, as disputas de mercado e dos domínios políticos entre as nações repercutiram na produção e circulação da informação, gerando o fenômeno da explosão informacional, vetor da necessidade das atividades de mediação da informação. Frente a esse quadro de alta complexidade que perpassa todo o processo de produção e comunicação do conhecimento ganhou relevo a compreensão acerca da dinâmica da geração e uso da informação, o que motivou o aparecimento dos estudos 
em torno dos fluxos informacionais, nos quais os usuários adquiriam status de categoria determinante do processo, cuja satisfação de suas necessidades consiste em um dos elementos centrais e constitutivos das metas do trabalho com a informação.

\section{O foco no usuário e a emergência da mediação para a apropriação da informação}

Os estudos sobre os comportamentos e as necessidades dos usuários (estudos de usuários) passaram a nortear o desenvolvimento e a inovação dos serviços de disseminação da informação, colocando o usuário da informação em realce e apontando a urgência da criação de atividades mediadoras do acesso e uso da informação (domínio da mediação).

Por outro lado, a tomada de consciência sobre a emergência das atividades de mediação direta da informação foi insuficiente para assegurar, de imediato, uma mudança substancial no fazer informacional, embora tenha representado um avanço em termos dos estudos, pesquisas e reflexões em torno das características do processo de mediação, focalizando suas variáveis constitutivas e intervenientes.

Para abordar a questão da mediação, torna-se imprescindível assinalar que esta consiste em uma ação ligada à vida, ao movimento e ao processo de construção de sentidos. Ela se caracteriza como uma ação humana que nasce a partir do contato do sujeito com a realidade e do contato atribuído por este a essa realidade. (GOMES, 2010). Isso significa dizer que a mediação da informação tem origem nas interações sociais e nas mediações simbólicas, razão pela qual a linguagem é um elemento singular, ao sustentar a experiência humanizadora do viver em comum, do conviver. A linguagem é sustentáculo das interações sociais e estruturante das relações humanas.

A formação dos sentidos é dependente das experiências vividas pelo sujeito, pelos saberes que este teve a oportunidade de construir. No contato com o mundo o homem lida com objetos de percepção com dimensões imediatas e mediadas, por meio dos quais segue construindo e reconstruindo sua compreensão sobre si mesmo, sobre os outros e sobre o seu meio. Os objetos de percepção imediata são percebidos através dos sentidos e sinais derivativos deles próprios. Já os objetos de percepção mediata têm um terceiro outro como elemento de mediação para o desenvolvimento da percepção. Os saberes e conhecimentos construídos são objetos de percepção mediada, isto é, dependentes das linguagens, que consistem em elemento primeiro e fundamental no processo da mediação. Como ressalta Vygotsky (1991), na mediação a linguagem, a palavra e a fala têm importância fundamental.

A mediação está relacionada ao processo de comunicação e requer a diferença, a alteridade e a relação. (FOLSCHEID, 1990). Não há possibilidade de efetividade na mediação quando se negligencia que a comunicação lhe é cara, quando se deixa de considerar que há uma relação em curso entre os sujeitos da partilha e os sujeitos mediadores 
dessa partilhar, na interação entre esses diferentes "outros", o "outro" mediador é o terceiro que age com, estimulando o colocar em comum, favorecendo o fazer com o "outro", realizando e fomentando a ação do compartilhamento dos saberes.

Quando se trata da mediação da informação, colocada em curso pelo ambiente biblioteca, torna-se importante a compreensão de duas dimensões do objeto informação, a dimensão da sua materialidade e também da sua imaterialidade. No que tange aos registros, à formação de coleções, representação e organização dessas coleções para divulgação, disseminação e recuperação da informação, o trabalho informacional essencialmente se relaciona às características da materialidade desse objeto, Mas, ao conduzir o trabalho informacional em consonância com a diversidade cultural, procurando mediar o uso proficiente e favorecedor do processo de apropriação dos conteúdos, a biblioteca necessariamente precisa trabalhar com os aspectos imateriais da informação.

Essas duas dimensões se articulam para que a mediação favoreça a produção, circulação e apropriação da informação, o que pressupõe a existência de dispositivos que são, conforme assinala Peraya (1999), de natureza técnica, semiológica e pragmática. A mediação da informação pressupõe técnicas, instrumentos, suportes, recursos, agentes e processos que se caracterizam como dispositivos produtores de sentidos. A própria biblioteca se constitui em um dispositivo com uma função social definida (natureza pragmática), que se organiza dentro de uma lógica e a partir da adoção de métodos, linguagens, técnicas, processos e instrumentos (natureza técnica). E para assegurar o acesso e uso da informação, visando que os sujeitos possam se apropriar dos conteúdos, a biblioteca desenvolve ações que exigem a articulação desses elementos, sob uma ordem informacional dialógica (PIERRUCCINI, 2007), potencializadora da produção de sentidos, assumindo, então, sua natureza semiológica, que assume papel relevante ao domínio da construção e fortalecimento da identidade social.

A consciência de que a biblioteca é um "organismo vivo" realça seu atributo de dispositivo de mediação, como demanda o exercício do seu autoconhecimento. Os profissionais que atuam na biblioteca, que lhe conferem "vida", enfrentam o desafio de refletir sobre seus fundamentos, lógicas de funcionamento e atuação, conferindo suas transformações dentro do seu percurso histórico na sociedade. Compreender a vida que se manifesta e é produzida pelo próprio ambiente ao longo da sua história, significa a possibilidade de compreensão dos paradigmas sob os quais a sua existência social vem se dando. Na perspectiva de Perrotti e Pieruccini (2007), a história da biblioteca nos permite identificar que está atuou sob três paradigmas:

a)o paradigma da conservação cultural, no qual o principal foco de suas atividades esteve concentrado na organização e representação da informação para a conservação e preservação da memória; 
b)o paradigma da difusão cultural, quando as atividades para garantir a recuperação, o acesso e o uso da informação ganhara importância;

c)o paradigma da apropriação cultural, que passou a assinalar a relevância das ações de mediação direta para favorecer 0 acesso e uso da informação, privilegiando a dialogia, a troca de informações, o compartilhamento e o debate em torno delas, condições necessárias ao processo de construção do conhecimento e apropriação dos conteúdos, substrato da formação de protagonistas sociais e culturais.

Quando se analisa as perspectivas subjacentes a esses paradigmas, pode-se observar que cada um deles faz com que a biblioteca atue mais fortemente em domínios distintos. O paradigma da conservação cultural conduz a biblioteca a uma atuação sob o domínio da formação e conservação da memória. O paradigma da difusão cultural pode ser considerado como precursor do domínio da mediação, já que dá início ao processo de consideração das perspectivas e necessidades dos usuários, sendo o paradigma da apropriação cultural aquele que efetivamente convida a biblioteca para uma atuação de mediadora, sob o foco da formação e fortalecimento da identidade social.

O paradigma da apropriação cultural, ao focalizar o domínio da identidade social coloca a biblioteca na rota da mediação da informação que, conforme ressalta Almeida Júnior (2008, p. 3), representa

[...] toda ação de interferência-realizada pelo profissional da informação-direta ou indireta; consciente ou inconsciente; singular ou plural, individual ou coletiva; que propicia a apropriação de informação que satisfaça, plena ou parcialmente, uma necessidade informacional.

O conceito de Almeida Júnior alerta para os subgrupos das ações mediadoras desenvolvidas no ambiente da biblioteca: as consideradas como atividades meio, a exemplo daquelas relacionadas à representação e organização da informação, que podem ser categorizadas como atividades de mediação implícita, e aquelas consideradas como atividades fins, como as atividades dos serviços de referência, sendo, portanto, categorizadas como atividades de mediação explícita.

A partir desse conceito de mediação da informação, emergente do esforço reflexivo que se desenvolve à luz do paradigma da apropriação cultural, a mediação passa a ser vista como a base de todo o fazer do profissional da informação, vindicando deste uma consciência quanto à sua responsabilidade social na construção de um espaço social, o ambiente da biblioteca, organizado e vivente na lógica do dialogismo e para a construção de sentidos.

Nesse sentido, defendemos que a biblioteca pública, para cumprir sua missão social, deve atuar transitando sob a integração dos três 
paradigmas: o da conservação cultural, porque não pode abandonar o domínio da memória, já que deve promover a integração da herança cultural e também da diversidade; o da difusão porque este orienta seu trabalho de organizar para assegurar a recuperação e o acesso à informação e o da apropriação cultural, já que a biblioteca pública tem inclusa na sua missão a promoção do exercício da expressão e criatividade dos sujeitos e coletivos sociais, elementos fundamentais para a formação de protagonistas sociais, contribuindo, assim, para a construção e o fortalecimento da identidade social. Posicionando-se na zona de interseção desses três paradigmas a biblioteca pública potencializará suas ações em favor da memória, da mediação e da identidade social, o que Ihe conferirá o perfil de um dispositivo de mediação cultural.

Ao assumir sua condição de dispositivo de mediação cultural, a biblioteca pública necessariamente estabelecer-se-á a partir de uma "ordem informacional dialógica" que implica na adoção de configurações que garantam ao seu ambiente as características de um espaço informacional, apresentando um repertório cultural diversificado e que espelhe o seu contexto social, adotando linguagens informacionais adequadas à representação, organização e recuperação ágil da informação, contando com mediadores capacitados e aptos ao exercício da comunicação sensível e acolhedora. Além disso, nessa perspectiva a biblioteca pública compromete-se com o desenvolvimento de práticas informacionais dialógicas, tanto no que tange às atividades culturais que desenvolve e promove, quanto àquelas ligadas às suas próprias práticas de gestão. (PIERRUCCINI, 2007).

Conforme Pierruccini (2007), as configurações e as práticas dos dispositivos são imprescindíveis ao processo de mediação. Estas falam, narram, significam, gerando sentidos e significados para os sujeitos, portanto, integram as condições necessárias ao cumprimento da missão social da biblioteca.

De acordo com a Declaração universal sobre a diversidade cultural (UNESCO, 2002) e o Manifesto IFLA/UNESCO sobre bibliotecas públicas (UNESCO, 1994), a biblioteca pública deve assegurar a transmissão e promoção cultural; resgatar o diálogo entre a herança e a diversidade cultural, integrando-se a comunidade; contribuindo para o exercício da expressão e criatividade da comunidade; assegurando o acesso e uso da informação, e a produção do conhecimento; contribuindo para o processo de democratização da cultura. (UNESCO, 1994). Ao se analisar o que preconiza esse Manifesto, verifica-se a articulação dos domínios da memória, da mediação e da identidade social, ressaltando-se que a atuação na dimensão da construção identitária e cultural coloca a biblioteca pública frente ao desafio de se ressignificar enquanto um dispositivo de mediação voltado à apropriação da informação, à apropriação cultural, constituindo-se como um espaço colaborativo na construção do protagonismo cultural e social.

A dimensão da construção identitária e cultural coloca à biblioteca pública frente ao desafio de atuar e desenvolver ações dialógicas; de promover o processo de negociação dos sujeitos com o mundo material, 
social e simbólico, contribuindo para a formação de protagonistas sociais e culturais; para a construção da própria cultura e da identidade social, enfim, considerando o que preconiza o paradigma da apropriação cultural, ainda que a biblioteca pública não possa afastar-se radicalmente dos paradigmas da conservação e difusão cultural.

Ao colocar-se como uma biblioteca de apropriação cultural, sua atenção deve se voltar às dez condições que Perrotti (2010) aponta como indispensáveis ao comportamento desse dispositivo, que são:

a) postura de acolhimento - espaço educativo e cultural que acolhe e reconhece as diferenças e singularidades da comunidade;

b) atitude de projeção - projeta a comunidade rumo ao conhecimento;

c) fomentar a cooperação - local de fomento a parcerias, trocas e ações cooperativas;

d) proporcionar e desenvolver sinergia - espaço de articulação de saberes;

e) assumir comportamento pró-ativo quanto ao desenvolvimento e implantação de políticas públicas - atuar pelo desenvolvimento de políticas voltadas ao protagonismo social e cultural;

f) favorecer a formação, conservação e o acesso à memória coletiva - constituir e disponibilizar acervos diversificados;

g) cultivar e estimular a dialogia - assumindo a função de local de interlocuções e trocas simbólicas;

h) saber redesenhar-se - redefinindo permanentemente suas práticas culturais e a atuação de seus profissionais (constituição do mediador da informação);

i) constituir-se enquanto uma estação cultural promovendo a produção e ressignificação dos saberes;

j) atuar no foco da infoeducação - orientando e também educando para o mundo informacional.

Essas condições asseguram a biblioteca pública o perfil de dispositivo cultural, no entanto, a ação mediadora que está subjacente à concretização de cada uma dessas condições, para potencializar a formação de protagonistas culturais e sociais, meta maior do paradigma da apropriação, demanda a adoção de condutas e comportamentos de afetividade, sensibilidade, flexibilidade, disponibilidade, interesse, organização, e também o domínio de tecnologias, recursos, instrumentos, técnicas e processos informacionais, o que Pierruccini (2007) denominou de categorias do dispositivo informacional dialógico. 
Pode-se então compreender que os novos desafios que se apresentam para a biblioteca na contemporaneidade são os de compreender como organizar a informação para diversos tipos de usuários, observando a relação entre organização e mediação da informação; de considerar as origens que fundamentam historicamente e epistemologicamente a sua existência enquanto um ambiente de informação e de cultura; de assumir os atributos de um dispositivo cultural de natureza técnico-semio-pragmática, como caracteriza Peraya (1999), assumindo-se, por fim, como uma midiasfera que, conforme Debray (2000) consiste em um ambiente de transmissão e comunicação que confere um sentido de ação, acolhimento e interligação com o próprio desenvolvimento cognitivo, social e cultural dos indivíduos e da sociedade.

\section{Considerações finais}

Os domínios da memória, da mediação e da identidade social se interligam nas ações humanas de produção, preservação, circulação, recuperação e disseminação dos saberes e culturas, ações estas que encontram no ambiente biblioteca, e em especial na biblioteca pública, um espaço social de acesso e uso da informação, potencializador do processo de apropriação cultural, intrínseco à formação de protagonistas sociais.

Dentre esses domínios, a mediação da informação ganha destaque por sua centralidade nas interações sociais e mediações simbólicas, passando a ser compreendida como uma ação inerente a todo fazer do profissional da informação, dando maior relevo à responsabilidade social desse agente mediador e também do ambiente biblioteca enquanto espaço de construção de sentidos.

No entanto, a centralidade da mediação não afasta da biblioteca suas demais funções sociais, ao contrário exige maior excelência na adoção de técnicas e processos de representação da informação e organização do conhecimento, considerando-se os diferentes contextos sociais; demanda ainda que se avalie e contemple os aspectos cognitivos envolvidos na apropriação da informação, assim como a responsabilidade pelo desenvolvimento de competências para a identificação, localização, utilização e produção da informação, assegurando também a preservação da memória social. Em síntese, cabe à biblioteca atuar como um dispositivo de mediação cultural e como uma midiasfera, favorecedora dos processos de construção da autonomia e da cidadania.

Cabe à biblioteca pública, como a qualquer outro tipo de biblioteca, o domínio compreensivo do fenômeno informação para avançar na sua organização; assegurar a preservação da memória cultural; realizar a mediação como atividade central na construção de uma interlocução promissora com os usuários, compreendendo que essa interlocução (dialogia - comunicação) situa-se na base do processo de aprendizagem, de construção do conhecimento, da cultura, da cidadania e da identidade social. Por fim, a biblioteca pública não pode abdicar da sua atuação nos domínios da memória, da mediação e da identidade social, já que estes circunscrevem sua própria existência. 


\section{Referências}

ALMEIDA JÚNIOR, Oswaldo Francisco de. Mediação da informação e múltiplas linguagens. In: ENCONTRO NACIONAL DE PESQUISA EM CIÊNCIA DA INFORMAÇÃO, 9., 2008, São Paulo. Anais... São Paulo: Universidade de São Paulo, 2008. 1 CD-ROM.

DEBRAY, Régis. Transmitir: o segredo e a força das idéias. Petrópolis: Vozes, 2000.

FOLSCHEID, D. "Médiation". In: JACOB, André. Les notions philosophiques: dictionnaire. Paris: Presses Universitaires de France, 1990. p. 1584-1585.

GOMES, Henriette F. Tendências de pesquisa sobre mediação, circulação e apropriação da informação no Brasil: estudo em periódicos e anais dos ENANCIB (2008-2009). Pesquisa brasileira em Ciência da Informação, Brasília, v. 3, n. 1, p. 85-99, jan./dez. 2010.

MANGUEL, Alberto. Uma história da leitura. São Paulo: Companhia das Letras, 1997.

PERAYA, Daniel. Médiation et médiatisation: le campus virtuel. Hermès, Paris, n. 25, 1999. Disponível em: <http://documents.irevues.inist.fr/handle/2042/14983>. Acesso em: 25 jun. 2010.

PERROTTI, Edmir. Infoeducação, 2010. Slides das aulas da disciplina Mediação e Apropriação da Informação, ministrada no Programa de PósGraduação em Ciência da Informação da UFBA, jun. 2010.

PERROTTI, Edmir; PIERUCCINI, Ivete. Infoeducação: saberes e fazeres da contemporaneidade. In: LARA, Marilda L. Ginez de; FUJINO, Asa; NORONHA, Daisy P. (Org.). Informação e contemporaneidade: perspectivas. Recife: Néctar, 2007. p. 47-96.

PIERRUCCINI, Ivete. Ordem informacional dialógica: mediação como apropriação da informação. In: ENCONTRO NACIONAL DE PESQUISA EM CIÊNCIA DA INFORMAÇÃO, 8., 2007, Salvador. Anais... Salvador: PPGCI/UFBA; ANCIB, $2007 . \quad$ Disponível em: <http://www.enancib.ppgci.ufba.br/artigos/GT3--159.pdf>. Acesso em: 8 jul. 2013.

UNESCO. Declaração universal sobre a diversidade cultural. 2002. Disponível em: <http://unesdoc.unesco.org/images/0012/001271/127160por.pdf>.

Acesso em: 25 mar. 2013.

UNESCO. Manifesto IFLA/UNESCO sobre bibliotecas públicas. 1994. Disponível em: <http://archive.ifla.org/VII/s8/unesco/port.htm>. Acesso em: 21 set. 2013.

VYGOTSKY, L. A formação social da mente. São Paulo: Martins Fontes, 1991. 
